\title{
Subendocardial Myocardial Infarction by ECG Finding
}

National Cancer Institute

\section{Source}

National Cancer Institute. Subendocardial Myocardial Infarction by ECG Finding. NCI

Thesaurus. Code C35305.

An electrocardiographic finding of an injury in leads corresponding to the anatomic region

of the subendocardial layer of the wall of the heart. 